\title{
Activation of metalloproteinases and their association with integrins: an auxiliary apoptotic pathway in human endothelial cells
}

\author{
B Levkau ${ }^{1,3}$, RD Kenagy ${ }^{2}$, A Karsan ${ }^{4}$, B Weitkamp ${ }^{3}$, \\ AW Clowes ${ }^{2}$, R Ross ${ }^{1}$ and EW Raines ${ }^{*, 1}$ \\ ${ }^{1}$ Department of Pathology, University of Washington, Seattle, WA, USA \\ 2 Department of Surgery, University of Washington, Seattle, WA, USA \\ ${ }^{3}$ Institute of Atherosclerosis Research, University of Münster, Germany \\ ${ }^{4}$ Department of Pathology and Laboratory Medicine, University of British \\ Columbia, Vancouver, BC, Canada \\ * Corresponding author: EW Raines, Department of Pathology, Harborview \\ Medical Center, 325 Ninth Avenue, Box 359675, Seattle WA 98104-2499, USA. \\ Tel: 206-341-5410; Fax: 206-341-5416; E-mail: ewraines@u.washington.edu
}

Received 26.3.02; revised 19.6.02; accepted 25.7.02

Edited by D Altieri

\begin{abstract}
Anchorage of cells to the extracellular matrix and integrinmediated signals play crucial roles in cell survival. We have previously shown that during growth factor deprivationinduced apoptosis in human umbilical vein endothelial cells (HUVECs), key molecules in focal adhesions and adherens junctions are cleaved by caspases. In this study we provide evidence for a selective upregulation of cell-associated matrix metalloproteinases (MMPs). We observe a physical association of MMP2 with $\beta 1$ and $\alpha v$ integrins, which increased threeto fourfold during apoptosis and is dependent upon integrin $\beta 1$ levels and activation state. Both enforced activation of $\beta 1$ integrin by a specific antibody and inhibition of MMPs protect HUVECs from apoptosis. We hypothesize that, prior to the commitment to apoptosis, 'inside-out' signals initiated by the apoptotic stimulus alter cell shape together with the activation states and/or the availability of integrins, which promote matrix-degrading activity around dying cells. This 'auxiliary' apoptotic pathway may interrupt ECM-mediated survival signaling, and thus accelerate the efficient execution of the cell death program.

Cell Death and Differentiation (2002) 9, 1360 - 1367. doi:10.1038/

sj.cdd. 4401106
\end{abstract}

Keywords: extracellular matrix; TIMP2; MT1-MMP; focal adhesion

Abbreviations: ECM, extracellular matrix; FACS ${ }^{\mathbb{R}}$, fluorescenceactivated cell sorting; GFs, growth factors; HUVECs, human umbilical vein endothelial cells; MMPs, matrix metalloproteinases; MT-MMPs, membrane-type matrix metalloproteinases; TIMPs, tissue inhibitors of metalloproteinases; TNF $\alpha$, tumor necrosis factor $\alpha$; uPA, urokinase-type plasminogen activator; VEGF, vascular endothelial growth factor; ZVAD-fmk, benzoyloxycarbonyl1-ValAla-Asp fluoromethyl ketone

\section{Introduction}

Human umbilical vein endothelial cells (HUVECs) undergo apoptosis when deprived of growth factors (GFs). Endothelial cells in organs preserved in low or no serum conditions for transplant appear particularly vulnerable to apoptosis, ${ }^{1,2}$ and vascular endothelial growth factor (VEGF) deprivationinduced apoptosis is a component of capillary regression in vivo. ${ }^{3,4}$ Among the first morphologic changes after induction of apoptosis by removal of GFs are loss of focal adhesions and retraction from the extracellular matrix $(E C M) .{ }^{5}$ During this process, key molecules in focal adhesions and in adherens junctions are cleaved by caspases. ${ }^{5,6}$ We have previously suggested that specific signaling ${ }^{7}$ and architectural components ${ }^{5,6}$ are modified during the disassembly of cellmatrix and cell-cell contacts in the apoptotically dying cell, thus contributing to and propagating the apoptotic process by actively interrupting survival signals from the ECM and neighboring cells.

The ECM plays a critical role in determining the fate of a cell. $^{8}$ Anchorage of cells to the ECM has been implicated in their survival, ${ }^{9}$ since its prevention induces apoptosis in endothelial and epithelial cells in vitro and in vivo. ${ }^{9-12}$ Integrins are the architectural and signaling mediators that link the ECM with the focal adhesion complex. This complex acts as an integrative module for incoming signals, and orchestrates the intricate interrelationship between the ECM, the cytoskeleton, and signaling cascades. ${ }^{13-16}$ Interference with integrin-mediated survival signals, either by depriving cells of $\mathrm{ECM}^{10,11}$ or destroying their ECM environment by misexpression of matrix metalloproteinases (MMPs), leads to apoptosis. ${ }^{17}$ Inversely, inhibition of MMPs during the involution of the mammary gland after lactation, prevents the scheduled apoptosis of alveolar epithelium and delays mammary involution. ${ }^{12,18}$ Therefore it appears that epithelial and endothelial cell survival is dependent on signals from integrins and the regulated proteolysis of their ECM ligands.

The extremely efficient process of endothelial cell disengagement from the ECM that we observe after induction of apoptosis prompted us to examine whether dying HUVECs activate endogenous mechanisms to actively promote detachment from the ECM and whether this may serve to accelerate apoptosis. In particular, we examined alterations in integrin function and MMP activities and their involvement in the apoptotic process.

\section{Results \\ MMPs and uPA are increased during endothelial apoptosis}

Integrin-mediated signals depend upon the ECM components encountered, and destruction of the ECM by matrix-degrading 
enzymes induces apoptosis in vivo and in vitro, presumably by disengaging integrins. ${ }^{17}$ Therefore, we tested whether the apoptotic stimulus induces the matrix-degrading enzymes of the dying cell. After $12 \mathrm{~h}$ of GF withdrawal, detached, apoptotic endothelial cells accounted for $40-45 \%$ of the total cell population. ${ }^{7}$ By gelatin zymography, we observed a distinct upregulation in apoptotic cells of the 65 and $60 \mathrm{kDa}$ forms of MMP2, which corresponded to the intermediate $(2.5 \pm 0.2$-fold increase) and active form (2.3 \pm 0.3 -fold increase), respectively, compared with controls (Figure 1A). Western blots confirmed these results (data not shown), and analysis of the conditioned medium revealed an increase with time in both the pro-enzyme and processed forms of MMP2 during apoptosis (Figure 1B, neo-conditions, and Figure 2).

To exclude the possibility that the endogenous activation of MMP2 results from an absence of MMP inhibitors present in the regular growth media, we used HUVECs retrovirally transduced with $\mathrm{Bcl}-2$, which are resistant to GF deprivation-induced apoptosis. ${ }^{19}$ These cells showed no major MMP2 activation after GF deprivation, whereas the transduced control cells exhibited a time-dependent activation of MMP2, associated with the cell and in the conditioned media (Figure 1B).

Plasminogen activation has been associated with the degrative phase in macrophage apoptosis. ${ }^{20}$ Therefore, we examined whether other proteolytic enzymes involved in ECM degradation are induced during apoptosis and found
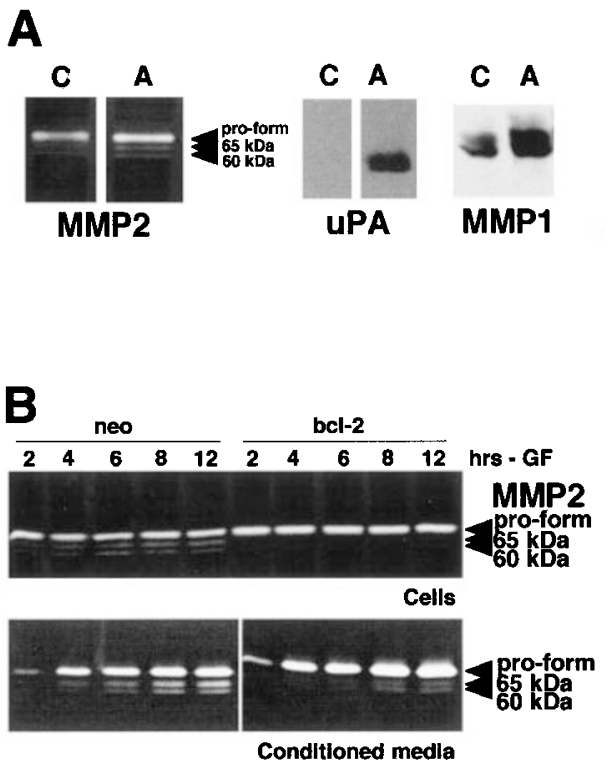

Figure 1 Differential regulation of MMPs and UPA during endothelial apoptosis. (A) Changes in MMP2 (top left) are shown in a representative gelatin zymography $(n=10)$ of cell lysates from control cells $(C)$ and apoptotic HUVECs (A) $12 \mathrm{~h}$ after GF removal (10 $\mu \mathrm{g}$ protein/lane). The major band is the inactive pro-form of MMP2, the $65 \mathrm{kDa}$ band is the intermediate MMP2 form, and the $60 \mathrm{kDa}$ form represents active MMP2. A casein/plasminogen zymography for uPA (top center) and immunoblotting for MMP1 (top right) were performed on cell lysates from the same cell populations as described and are representative of two and three replicate experiments, respectively. (B) HUVECs overexpressing either Bcl-2 or the neomycin resistance gene alone were deprived of GFs for the indicated times, and $10 \mu \mathrm{g}$ of cell lysates of pooled cell populations and the corresponding conditioned media (1\% v/v) were subjected to gelatin zymography. The data are representative of three replicate experiments that MMPs were differentially regulated during apoptosis: whereas MMP3 and MMP9 were not detected by zymography in cells, and the low levels of the latter in the conditioned media did not change (data not shown), the expression of MMP1 was increased in apoptotic cells compared with control cells (Figure 1A). A different type of matrix-degrading enzyme, urokinase-type plasminogen activator (UPA), also increased after GF deprivation, as seen on casein/plasminogen zymograms (Figure 1A): UPA was low in control cells and significantly induced in apoptotic cells. Again, Bcl-2 overexpression in HUVEC that protects them from GF-induced apoptosis reduced the increase in UPA after GF withdrawal (data not shown).

\section{Metalloproteinase-mediated activation of MMP2 and inhibition of MMP activity are protective}

The MMP inhibitor BB-94, but not the 1000-fold less effective BB-374, potently prevented the activation of MMP2, both in cells and in the conditioned media, during apoptosis, whereas it had no effect on the upregulation of uPA (Figure 2 and data not shown). This observation suggested an MMP-dependent process of MMP2 activation during apoptosis. Therefore, we tested whether enzymes of the family of membrane-type matrix metalloproteinases (MT-MMPs) known to activate MMP2 $^{21}$ play a role in our system. We evaluated levels of MT1-MMP known to be involved in MMP2 activation by Western blot analysis (Figure $3 \mathrm{~A}$ ). In apoptotic cells, native MT1-MMP is processed to a $40-44 \mathrm{kDa}$ fragment consistent with autoprocessing of MT1-MMP. ${ }^{22}$

Although MT-MMP activity cannot be measured directly, we made use of its differential susceptibility to inhibition by tissue inhibitors of metalloproteinases (TIMPs): low levels of TIMP2 are required for MT1-MMP-mediated MMP2 activation, but high levels of only TIMP2, and not TIMP1, can inhibit activation of MMP2 by MT1-MMP. ${ }^{17,23}$ In our system, addition of recombinant TIMP2 was as effective as BB-94 in preventing the appearance of the
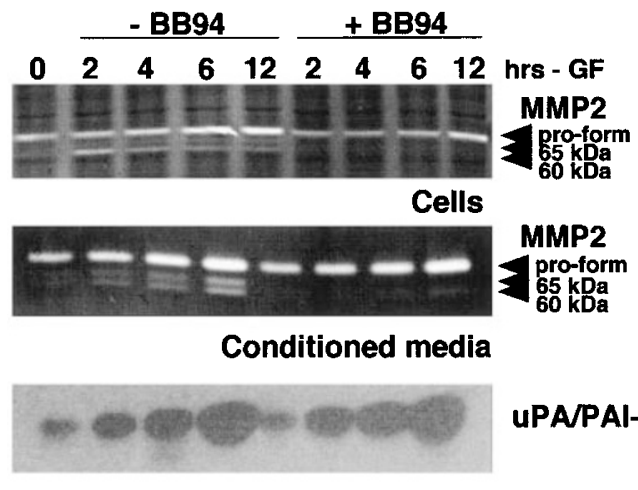

UPAPAI-1

\section{Conditioned media}

Figure 2 The metalloproteinase inhibitor BB-94 inhibits the activation of MMP2 but not the increase of uPA during apoptosis. Gelatin zymography $(n=4)$ was performed on HUVEC lysates and conditioned media after GF deprivation in the presence or absence of $16 \mu \mathrm{M}$ BB-94 for the indicated times. Conditioned media from the same experiment were subjected to casein/ plasminogen zymography $(n=3)$. The major casein-degrading activity of approximately $80-85 \mathrm{kDa}$, corresponding to a uPA/PAI-1 complex, is shown in the third panel 
A
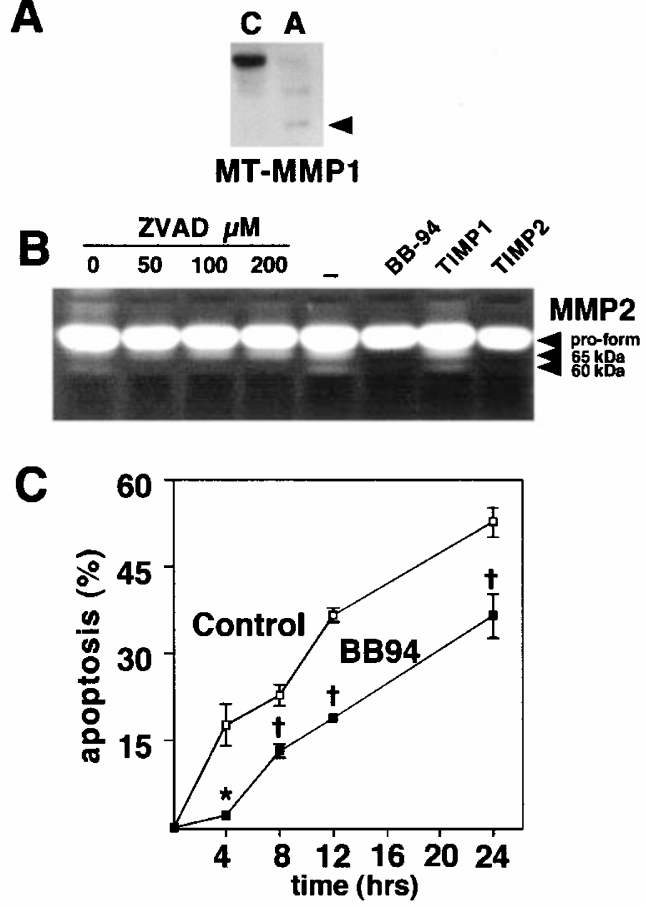

D
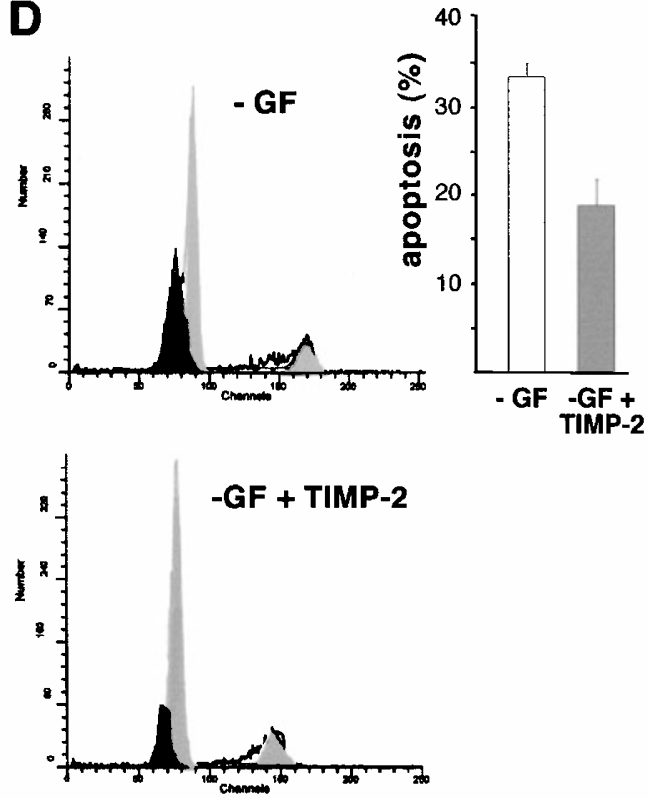

Figure 3 Metalloproteinase-mediated activation of MMP2 in apoptotic HUVECs and inhibition of apoptosis by BB-94 and TIMP2. (A) Western blot analysis for MT1MMP was performed on cell lysates of control (C) and apoptotic (A) HUVECs $12 \mathrm{~h}$ after GF removal (10 $\mu \mathrm{g} / \mathrm{lane})$. (B) Gelatin zymography of cell lysates from cells exposed to GF withdrawal for $12 \mathrm{~h}$ in the presence or absence of increasing concentrations of ZVAD-fmk (0-200 $\mu \mathrm{M})$, no additives ( -$)$, BB-94 (16 $\mu \mathrm{mol})$, TIMP1, or TIMP2 (each at $3 \mu \mathrm{g} / \mathrm{ml}$ ). (C) HUVECs were exposed to GF deprivation in the presence or absence of $16 \mu \mathrm{mol}$ BB-94 for the indicated times, and apoptotic floaters were expressed as per cent of total cell number. Each value represents mean \pm S.D. $(n=3)$, with ${ }^{*} P<0.02$ and $+P<0.009$, considered significant and very significant, respectively, by Welch $t$-test. (D) HUVECs were exposed to GF deprivation in the presence and absence of $9 \mu \mathrm{g} / \mathrm{ml} \mathrm{TIMP2}$. Gelatin zymography confirmed the inhibition of MMP2 activation (data not shown). DNA fragmentation (black peak) was analyzed by FACS ${ }^{\mathbb{R}}$ analysis, with quantitation of triplicate determinations shown in the bar graph
$65 \mathrm{kDa}$ and $60 \mathrm{kDa}$ forms of MMP2 during apoptosis, whereas TIMP1 had no effect (Figure 3B). This result implies that MT-MMPs are involved in MMP2 activation.

Caspases could also potentially contribute to the activation of MMP2. This possibility was examined with the potent inhibitor of caspases ZVAD-fmk. ZVAD-fmk inhibited the generation of the active $60 \mathrm{kDa}$ form of MMP2 in a dose-dependent manner, which was accompanied by a concurrent accumulation of the intermediate $65 \mathrm{kDa}$ form (Figure 3B). Thus, the processing of the intermediate to active MMP2 form appears to depend on both caspases and MT-MMPs. Although a plasmindependent mechanism of MMP2 activation has also been described, ${ }^{24}$ aprotinin had no effect on MMP2 activation (data not shown).

To test whether the endogenous activation of MMPs may contribute to apoptosis, we added the MMP inhibitor BB-94. Addition of BB-94 substantially decreased apoptosis with an $89 \%$ suppression of cell death $4 \mathrm{~h}$ after GF deprivation, $40-$ $45 \%$ suppression during the following $8 \mathrm{~h}$, and $24 \%$ at $24 \mathrm{~h}$ (Figure 3C). Thus, inhibition of MMPs was effective primarily at early stages following GF-deprivation. The role of MMP2 activation in apoptosis was further investigated by the examination of DNA fragmentation by FACS $^{\mathbb{R}}$ analysis $5 \mathrm{~h}$ after GF deprivation in the presence and absence of TIMP2 (Figure $3 \mathrm{C}$ ). In the absence of TIMP2, 33\% of the cells had significant DNA fragmentation, whereas only $19 \%$ were detected in the presence of TIMP2 (Figure 3D). Thus, both the broad-based MMP inhibitor BB-94 and TIMP2 significantly delay apoptosis in GF-deprived endothelial cells.

\section{During apoptosis the cellular localization of MT1-MMP and MMP2 is altered, and MMP2 is recruited to $\beta 1$ and $\alpha v$ integrins}

As MMP2 can bind to the $\alpha \mathrm{v} \beta 3$ integrin and colocalize with integrins at focal adhesion sites, ${ }^{25,26}$ we hypothesized that recruitment of MMP2 to integrins after an apoptotic stimulus may promote disengagement from the matrix. We compared the cellular localization of MT1-MMP and MMP2 with phosphopaxillin, a component of focal adhesions, by confocal microscopy in control cells and viable cells still adherent $1.5 \mathrm{~h}$ after GF deprivation (Figure 4A,B). Although these GFdeprived cells are still viable (not committed to apoptosis because re-addition of GFs rescues all cells), localization of staining for both MT1-MMP and MMP2 shifted to focal adhesion sites with GF deprivation. This contrasts with control cells in complete media with GFs in which MMP2 and MT1MMP were localized intracellularly and not associated with focal adhesion sites (Figure 4A,B).

To test whether MMPs physically associate with integrins, we immunoprecipitated $\alpha \mathrm{v}$ and $\beta 1$ integrins from control, viable (GF deprived but not committed to apoptosis), and apoptotic cells and tested the immunoprecipitates for enzymatic activity on gelatin zymograms. In $\alpha v$ immunoprecipitates, the main gelatinolytic activity is attributed to MMP2, which we confirmed by immunoblotting (Figure 4C). We observed more MMP2 in $\alpha \mathrm{v}$ immunoprecipitates from apoptotic cells (3.2 \pm 0.4 -fold over control, $n=3)$ and viable cells $(2.1 \pm 0.2$-fold higher than control, $n=3)$. In $\beta 1$ 
A
A MT1-MMP

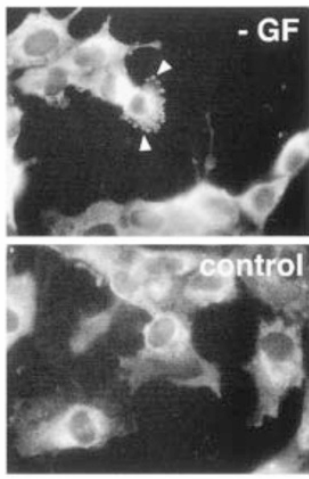

B

B MMP2

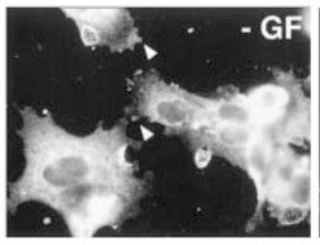

control

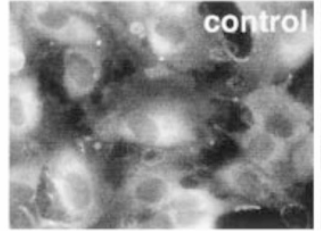

Phospho-paxillin

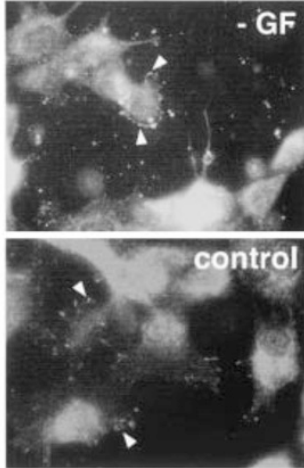

Phospho-paxillin

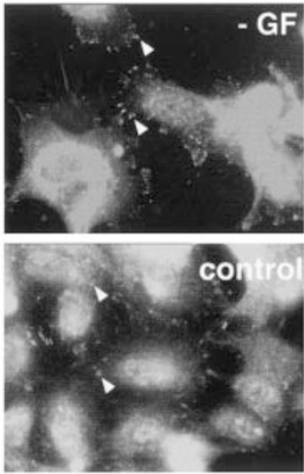

C
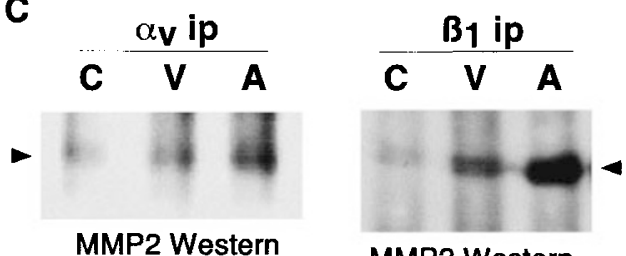

MMP2 Western
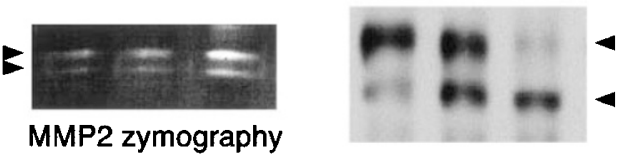

B1 Western
Figure 4 Focal adhesion localization of MT1-MMP and MMP2 during apoptosis and increased association of MMP2 with $\alpha \mathrm{V}$ and $\beta 1$ integrins. (A, B) Immunostaining for MT1-MMP (A) and MMP2 (B) was compared with that of phosphorylated ( $\mathrm{pY} 31$ )-paxillin by confocal microscopy for control and viable cells $1.5 \mathrm{~h}$ after GF removal. Arrows indicate focal adhesions. (C) $\alpha \mathrm{V}$ and $\beta 1$ integrins were immunoprecipitated from $250 \mu \mathrm{g}$ cell lysate from control (C), viable (V), and apoptotic cells (A) $12 \mathrm{~h}$ after GF deprivation, and the samples were subjected to gelatin zymography or Western blot analysis for MMP2 and $\beta 1$ integrin as noted. Altered proportions of differentially glycosylated forms of $\beta 1$ are observed in the different cell populations

immunoprecipitates, there was no MMP2 activity in zymograms (data not shown). However, after SDS-treatment and reduction of the samples, we detected MMP2 associated with $\beta 1$ on Western blots (Figure $4 \mathrm{C}$ ), which was increased in viable cells ( $3.13 \pm 0.3$-fold above controls, $n=3)$ and further
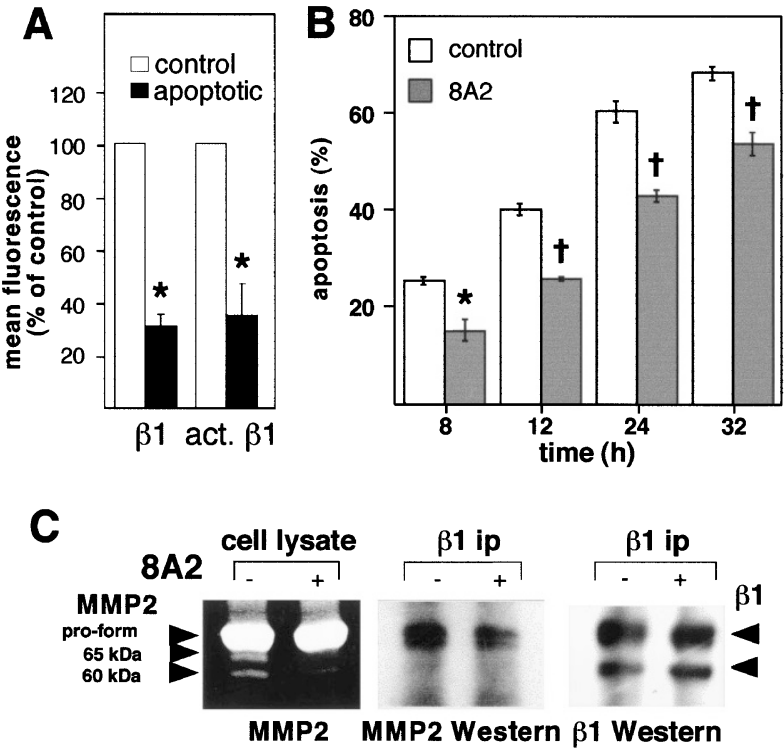

Figure 5 Regulation of cell surface integrin levels during apoptosis and the protective effect of $\beta 1$-activation. (A) FACS $^{\mathbb{R}}$ analysis of cell surface expression of integrins in control and apoptotic HUVECs is seen after $16 \mathrm{~h}$ of GF deprivation. Relative levels of integrin expression are the mean of three determinations in three different endothelial cell strains and are presented as per cent of the mean fluorescence for the individual integrins in control cells $\left({ }^{\star} P<0.01\right.$, Welch $t$-test used). (B) HUVECs were deprived of GFs in the presence or absence of $10 \mu \mathrm{g} / \mathrm{ml} \beta 1$-activating antibody $8 \mathrm{~A} 2$ for the indicated times, and detached apoptotic cells were expressed as per cent of total cell number. Each column represents mean + SD $(n=3)$, with ${ }^{*} P=0.0018$ and $+P<0.0008$ considered very significant and extremely significant, respectively (student $t$-test used). (C) HUVECs were deprived of GFs in the presence or absence of $10 \mu \mathrm{g} / \mathrm{ml}$ of the $\beta 1$-activating antibody $8 \mathrm{~A} 2$ for $12 \mathrm{~h}$, and the level of MMP2 in total cell lysates (pooled apoptotic and viable) and in immunoprecipitates with anti- $\beta 1$ antibody was evaluated by zymography and Western analysis, respectively

upregulated in apoptotic cells (4.22 \pm 0.5 -fold above controls, $n=3$ ). Therefore, it appears that MMP2 is actively recruited to $\alpha v$ and $\beta 1$ integrins during apoptosis. In the case of $\beta 1$, this occurs in spite of decreased levels and altered processing of the $\beta 1$ integrin (Figure $4 \mathrm{C}$ ).

\section{Integrin $\beta 1$ levels and activation state are decreased during apoptosis, and enforced activation of integrin $\beta 1$ is protective and suppresses recruitment of MMP2 to $\beta 1$ integrin}

Cell surface expression of integrin $\beta 1$ and activated $\beta 1$ were evaluated in control and apoptotic cells (Figure 5A). We detected a $65 \%$ reduction in the total cell surface levels of $\beta 1$ and activated $\beta 1$ (with a conformation-specific antibody) in apoptotic cells, compared with controls after $16 \mathrm{~h}$ (Figure 5A). To test whether the reduction in activated $\beta 1$ may contribute to apoptosis, we added a $\beta 1$-activating antibody, $8 \mathrm{~A} 2^{27,28}$ with GF deprivation. 8A2 substantially inhibited apoptosis up to $32 \mathrm{~h}$ after GF deprivation (Figure 5B). In a replicate experiment, the percentage of apoptotic cells after $10 \mathrm{~h}$ with $\beta 1$-activating antibody was $45 \pm 4 \%$, whereas the percentage of apoptotic cells was $67 \pm 6 \%$ after $10 \mathrm{~h}$ with a non-blocking antibody to $\alpha \mathrm{v}$ integrin. ( $n=3)$. 
To determine whether the association of MMP2 with $\beta 1$ is regulated by the $\beta 1$ activation state, we added the $\beta 1$ activating antibody $8 \mathrm{~A} 2$ during GF withdrawal. After $12 \mathrm{~h}$ of GF deprivation, less active MMP2 was observed in cells treated with $8 \mathrm{~A} 2(69 \pm 6 \%$ of untreated control; Figure $5 \mathrm{C})$, and decreased levels of MMP2 were found in $\beta 1$ immunoprecipitates from $8 \mathrm{~A} 2$-treated cells $(73 \pm 8 \%$ of untreated controls; Figure $5 \mathrm{C}$ ). Thus, recruitment of MMP2 to the $\beta 1$ integrin appears to be inversely correlated with the $\beta 1$ integrin activation state.

\section{Discussion}

\section{Possible mechanisms of MMP activation and recruitment to integrins during endothelial apoptosis}

Our studies demonstrate a selective regulation of ECMdegrading enzymes during HUVEC apoptosis: expression of MMP1 and UPA is increased, MMP2 is activated, active MT1 - MMP decreases with a loss of the pro-form, and MMP3 and MMP9 are unaffected. The ability of TIMP2, but not TIMP1, to inhibit the activation of MMP2 in our system implicates MT-MMPs in the activation of MMP2 during apoptosis, without excluding the possibility of autoactivation via a proximity mechanism. ${ }^{29}$ We observe that ZVAD-fmk prevents the generation of the active, but not the intermediate, MMP2 form, with an accumulation of the latter, suggesting that cellular changes preceding the commitment to apoptosis are involved in the generation of the intermediate MMP2 form, whereas the final processing of the intermediate to active MMP2 is dependent on both metalloproteinases and caspases. Such cellular changes may involve both suppression of integrin function and alteration of cytoskeletal architecture, as blockade of the $\alpha 5 \beta 1$ integrin in adherent fibroblasts activates MMP1 through Rac1-induced cell rounding and reduction of stress fibers. ${ }^{30}$ We have observed a dramatic change in the actin cytoskeleton early after GF deprivation. ${ }^{7}$ Actin depolymerization by cytochalasin $\mathrm{D}$, or a decrease of mechanical strain, induces MMP1 and activates MMP2. ${ }^{26,31-33}$ Additionally, integrin activation is sufficient to prevent MMP2 activation, even in a rounded cell. ${ }^{34}$

We have no evidence for direct activation of MMP2 by caspases. Incubation of recombinant caspases with proMMP2 does not result in an increase in gelatinolytic activity of MMP2 (data not shown). However, caspases may participate through indirect mechanisms. The generation of the fully active MMP2 from the intermediate form has been shown to be dependent on the autocatalytic activation in transit by active MMP2 bound to $\alpha \mathrm{v} \beta 3$ integrin. ${ }^{35}$ The increased association of MMP2 with integrins $\alpha \mathrm{V} \beta 3$ and $\beta 1$ in apoptosing cells may promote this mode of activation.

\section{Apoptotic stimulus} GF-deprivation

Cell shape change, loss of focal adhesion collapse of the cytoskeleton

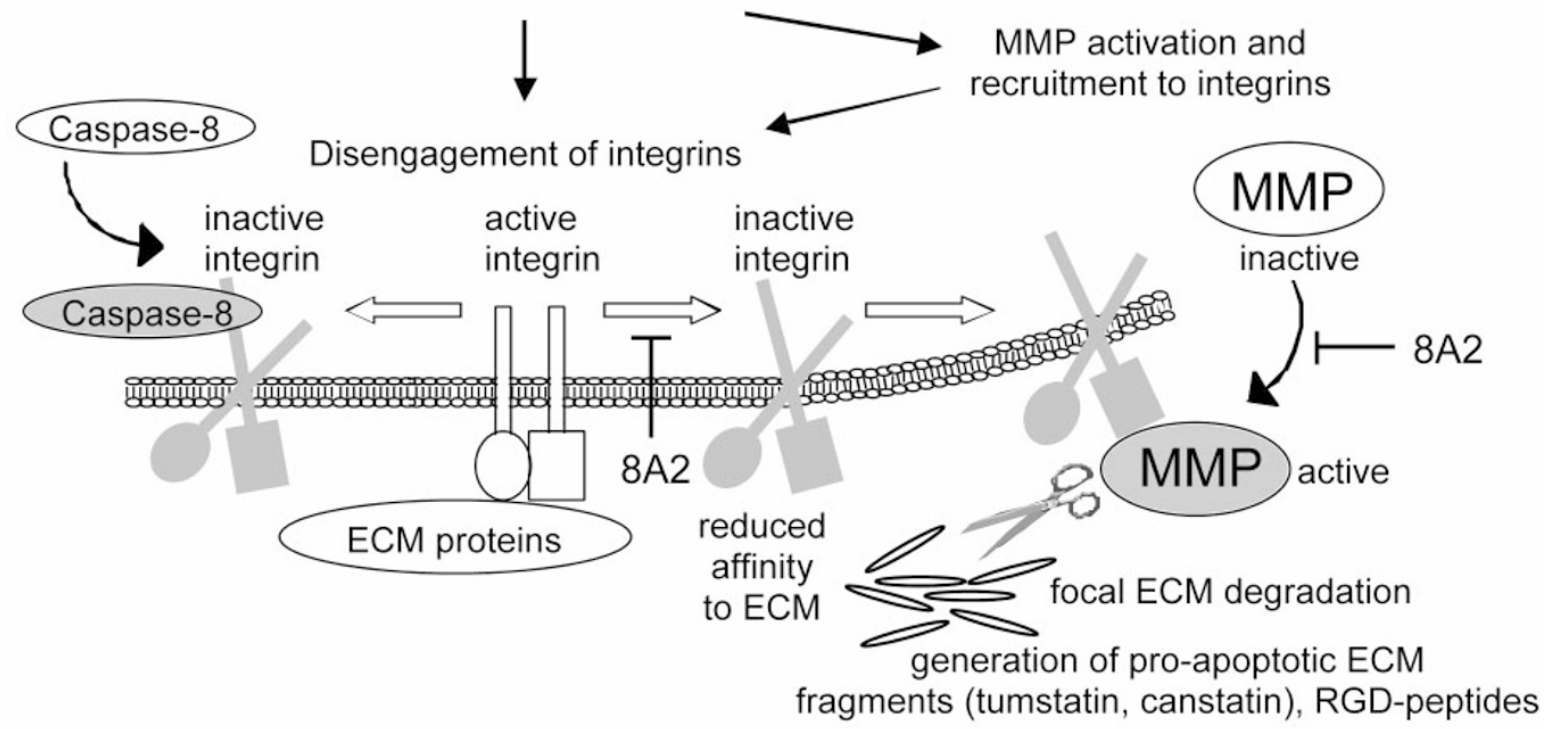

\begin{tabular}{|c|}
\hline $\begin{array}{c}\text { Integrin-mediated } \\
\text { death }(\mathrm{IMD})\end{array}$ \\
\hline
\end{tabular}

Loss of survival signals from the ECM

Figure 6 Schematic diagram of regulation of integrins and MMPs during endothelial apoptosis 
Caspases may participate in the generation of the close spatial proximity required for this mode of activation through conformational changes of the plasma membrane they induce during apoptosis, such as membrane blebbing mediated by cleavage and activation of Rho-activated kinase-I. ${ }^{36,37}$

Our data show a progressive increase in the association of MMP2 with $\alpha \mathrm{V}$ and $\beta 1$ integrins in HUVECs during apoptosis. Treatment of cells with the $\beta 1$-activating antibody $8 \mathrm{~A} 2$ decreases the association between MMP2 and $\beta 1$ and inhibits the activation of MMP2. However, our studies do not allow us to distinguish whether integrin activation or enhanced adhesion or both are responsible for the decreased association of MMP2 and the inhibition of MMP2 activation associated with $8 \mathrm{~A} 2$ treatment.

\section{Disruption of ECM-mediated survival signaling: a putative auxiliary pathway of apoptosis}

Endothelial cell shape is highly malleable to instructions provided by the ECM and is crucial for survival, suggesting a cell geometry permissive for or actively contributing to apoptosis. $^{38}$ Our study provides evidence for multiple mechanisms of endogenous cell shape regulation during apoptosis and supports a model in which the apoptotic program utilizes modulation of cell shape and interruption of ECM-derived survival signals for its own propagation.

It is conceivable that the downregulation of cell surface integrin expression during apoptosis, as detailed in this study, impairs integrin-mediated survival signaling. Reduced endothelial adhesion from inactivation of $\alpha \mathrm{v} \beta 3$ is observed after treatment with tumor necrosis factor $\alpha$ (TNF $\alpha$ ) and interferon- $\gamma$, which induces endothelial apoptosis in the vasculature of melanoma metastases in vivo. ${ }^{39}$ Activation of $\beta 3$ with a specific antibody restores adhesion and survival. Integrin activation with $\mathrm{Mn}^{+2}$ also attenuates endothelial apoptosis induced by combined treatment with TNF $\alpha$, interferon- $\gamma$, and melphalan. ${ }^{39}$ Our demonstration of a protective effect of enforced $\beta 1$ activation provides further support for the idea that decreased integrin levels and/or activation mediated through the integrin cytoplasmic domains may accelerate the apoptotic process in endothelial cells.

Although a substantial reduction in integrin levels is seen in the apoptotic cells (Figure 5A), the total levels of $\beta 1, \alpha \mathrm{V}$, and $\alpha \mathrm{v} \beta 3$ on the cell surface do not change during the first $4 \mathrm{~h}$ of GF deprivation $(100 \pm 15 \%, 88 \pm 13 \%$, and $96 \pm 7.9 \%$, respectively, by $\mathrm{FACS}^{\mathrm{B}}$ analysis). During this period, there is very little apoptosis $(7.3 \pm 5.6 \%)$, and the cells can be rescued by resupplementation of GF. However, dramatic alterations of cell shape occur during this period, including cell retraction, collapse of the actin cytoskeleton, and loss of focal contacts (Figure 4). ${ }^{5}$ These effects are reversible with re-addition of GF, consistent with the observation that disruption of focal adhesions is an early, but not irrevocable, event in endothelial cell apoptosis. ${ }^{40}$ Integrin disengagement from the matrix could either be the cause of, or result from, the loss of focal contacts that would lead to an increase in the proportion of 'free' integrins on the cell surface (Figure 6). However, the persistence of such free, unligated integrins has recently been shown to actively mediate a form of apoptosis termed 'integrin-mediated death' via the recruitment of caspase-8 to the cytoplasmic domain of the unligated integrin. ${ }^{41}$ This process is independent of the loss of adhesion per se (anoikis) and mediates endothelial apoptosis when endothelial cells are plated on an 'inappropriate' matrix. ${ }^{42}$

Inappropriate matrices may result from the degradation and alteration of the ECM by activated MMPs, as shown for the involution of the mammary gland, where ECM structures required for cell survival are lost through the activity of MMPs. ${ }^{12}$ In angiogenesis, increased association between MMPs and $\alpha \mathrm{v} \beta 3$ in endothelial cells plays a role in focal degradation of ECM. ${ }^{25}$ In our study, recruitment of MMP2 to integrins may serve to alter the matrix microenvironment of the integrin and disengage it from the ECM. Thus, unligated integrins would promote apoptosis by both loss of ECM-mediated survival signaling and active induction of apoptosis by integrin-mediated death (Figure 6). MMP inhibitors, such as BB94 and TIMP2, prevent MMP activation and protect against apoptosis, whereas 8A2 protects via an enforced activation (and engagement) of integrins. The difference between TIMP2 inhibition of apoptosis (43\%) and BB-94 inhibition (89\%) may reflect the broader inhibitory capabilities of BB-94, which also inhibits another class of metalloproteinases, the ADAMs, such as the TNF $\alpha$ convertase. ${ }^{43}$ The activation of UPA in our system may also contribute to apoptosis and thus account for the residual part of the apoptotic process that is unaffected by MMP inhibition (Figure 3 ). The notion that the uPA system may be involved in apoptosis is supported by findings that plasminogen activator inhibitor 1 inhibits apoptosis in the promotion of tumor growth. ${ }^{44}$

Proteolysis of ECM may itself promote the apoptotic process (Figure 6). A number of endogenous inhibitors of angiogenesis, such as endostatin, arresten, canstatin, and tumstatin, which bind to, or functionally disrupt, integrins, ${ }^{42}$ constitute fragments of basement membrane proteins. Several of these molecular fragments, such as tumstatin (the NC1 domain of $\alpha 3$ chain of type IV collagen) or canstatin ( $\alpha 2$ chain of type IV collagen), are potent inducers of apoptosis in endothelial cells. ${ }^{45,46}$ The generation of these fragments may be the result of both matrix synthesis/ deposition and proteolysis through matrix-degrading enzymes. Smaller RGD peptides induce apoptosis by direct activation of caspases, ${ }^{47}$ and it is conceivable that degraded matrix peptides containing the RGD sequence could contribute to apoptosis.

We previously described dissolution of focal adhesions during endothelial apoptosis and speculated that ECMmediated survival signals may be interrupted inside the cell by destruction of their intracellular mediators. ${ }^{5}$ Our present data suggest that such survival signals may be suppressed at the level of their receptors, the integrins, as well as through altering the integrin ECM ligands (Figure 6). In a positive regulatory manner, this auxiliary apoptotic pathway would inevitably lead to further impairment of integrinmediated survival signaling. Our studies demonstrate that removal of soluble GFs from endothelial cells results in a series of molecular events that interrupt critical ECM- 
integrin survival signaling and thus further accelerate the apoptotic process.

\section{Materials and Methods}

\section{Antibodies and reagents}

Antibodies were generously provided as indicated or purchased. For immunoblotting, MMP2 (Oncogene Research Products, Boston, MA, USA), human MMP1 (Howard Welgus, Parke-Davis, Ann Arbor, MI, USA), human MT1-MMP (Chemicon, Temecula, CA, USA), $\beta 1$ antisera (Richard Hynes, Massachusetts Institute of Technology, Cambridge, MA), $\alpha$ V, VNR139 (Gibco/BRL Products, Grand Island, NY, USA), and MAB1978 (Chemicon); for fluorescence-activated cell sorting (FACS ${ }^{\mathbb{R}}$ ) analysis, $\beta 1, \mathrm{P} 4 \mathrm{C} 10, \alpha \mathrm{V}$, and VNR147 (Gibco/BRL), activated $\beta 1,9 E G 7$ (PharMingen, San Diego, CA, USA); for activation of $\beta 1$ integrin, antibody $8 A 2$ (John Harlan, Harborview Medical Center, Seattle, WA, USA); for immunostaining MMP2 (Oncogene Research Products), MT1-MMP (Chemicon), and phosphospecific (pY31)-antipaxillin (Biosource, Camarillo, CA, USA). BB-94 and BB-374 were provided by British Bio-tech Products Limited, Abingdon, UK; benzoyloxycarbonyl1-Val-Ala-Asp fluoromethyl ketone (ZVAD-fmk) was purchased from Alexis Biochemicals, San Diego, CA.

\section{Cell culture and induction of apoptosis}

HUVECs were cultured in RPMI 1640 supplemented with $15 \%$ calf serum (Gibco/BRL), $3 \%$ endothelial cell growth supplement, ${ }^{48}$ and $50 \mu \mathrm{g} / \mathrm{ml}$ heparin (Sigma, St. Louis, MO, USA). ${ }^{5,7}$ Apoptosis was induced in confluent cell monolayers by incubating the cells in RPMI without GF supplementation. ${ }^{5,7} \mathrm{Bcl}$-2-overexpressing HUVECs were characterized previously. ${ }^{19}$

\section{Western blotting, immunoprecipitations, and zymography}

Cells were lysed in $50 \mathrm{mmol}$ Tris/ $\mathrm{HCl}, \mathrm{pH} 7.4,250 \mathrm{mmol} \mathrm{NaCl}, 0.5 \%$ NP- $40,10 \%$ glycerol, $5 \mathrm{mmol}$ EDTA, $50 \mathrm{mmol} \mathrm{NaF}, 0.5 \mathrm{mmol}$ $\mathrm{Na}_{3} \mathrm{VO}_{4}, 10 \mathrm{mmol} \beta$-glycerophosphate, $50 \mu \mathrm{g} / \mathrm{ml} \mathrm{PMSF}, 1 \mu \mathrm{g} / \mathrm{ml}$ leupeptin and aprotinin. Zymography was performed after electrophoresis in $10 \%$ polyacrylamide gels containing either casein or gelatin at $1 \mathrm{mg} / \mathrm{ml}{ }^{49,50}$ The gels were washed for $30 \mathrm{~min}$ after electrophoresis with $2.5 \%$ Triton $\mathrm{x}-100$ and then incubated with $50 \mathrm{mM}$ Tris, $10 \mathrm{mM} \mathrm{CaCl}_{2}, \mathrm{pH} 7.8$, for $18 \mathrm{~h}$ at $37^{\circ} \mathrm{C}$ and stained with Coomassie blue R. Incubations were performed in the presence and absence of $15 \mathrm{mM}$ EDTA to confirm metalloproteinase activity. For Western blot analysis, cell proteins were separated on 10\% SDSPAGE, and proteins were transferred to Immobilon membranes (Millipore, Bedford, MA, USA) and immunoblotted with specific antibodies. All immunoblots were visualized by chemiluminescence (Amersham Life Science Products, Arlington Heights, IL, USA). For detection of MMP2 association with integrins, either $\beta 1$ or $\alpha \mathrm{V}$ integrins were immunoprecipitated from $250 \mu \mathrm{g}$ cell lysate with $1 \mu \mathrm{l}$ anti- $\beta 1$ antibody or $4 \mu$ l of an anti- $\alpha$ v antibody (MAB1978). Experiments shown were repeated at least two times unless otherwise noted.

\section{Immunostaining to localize MT1-MMP, MMP2, and focal adhesions}

HUVECs were plated on gelatin-coated chamber slides, grown for $48 \mathrm{~h}$ at $37^{\circ} \mathrm{C}$ in media with GFs. Media were changed to that without GFs for the indicated times. At the end of the incubation, cells were fixed in $4 \%$ paraformaldehyde for $20 \mathrm{~min}$ at room temperature, washed two times with PBS, and permeabilized in $0.05 \%$ NP40 in PBS for $10 \mathrm{~min}$. After two additional washes with PBS, quenching was performed with three 5-min incubations with $50 \mathrm{mM} \mathrm{NH}_{4}$ acetate. Fixed cells were incubated with monoclonal antibodies to MMP2 (Oncogene Research Products) or MT1-MMP (Chemicon) or with polyclonal anti-phospho-paxillin (BioSource International) in $0.1 \%$ BSA/PBS for $1 \mathrm{~h}$ at room temperature followed by incubation with fluorescein-isothiocyanate-labeled anti-mouse IgG antibody (Cappel, Durham, NC, USA) or rhodamin-labeled anti-rabbit IgG (Cappel). Immunostaining was analyzed by confocal microscopy.

\section{FACS $^{\circledR}$ analysis of integrin levels and DNA fragmentation}

Cells fixed in $2 \%$ neutral buffered paraformaldehyde were incubated overnight at $4{ }^{\circ} \mathrm{C}$ with integrin antibodies for FACS ${ }^{\circledR}$ analysis with the use of a FACScan flow cytometer (BD Biosciences, San Diego, CA, USA). For analysis of DNA fragmentation, cells were fixed with icecold $70 \%$ ethanol and incubated in $1 \mathrm{ml}$ of PI staining solution $(50 \mu \mathrm{g} /$ $\mathrm{ml} \mathrm{PI}, 0.1 \mathrm{mg} / \mathrm{ml}$ RNAse A in $0.1 \% \mathrm{NP} 40$ and $0.1 \%$ trisodium citrate) for $20 \mathrm{~min}$ at $4{ }^{\circ} \mathrm{C}$. Flow cytometric DNA measurements were performed on a Coulter Epics Elite (Coulter, Krefeld, Germany). Propidium iodide fluorescence was detected at $625 \mathrm{~mm}$ with an argon ion laser $(488 \mathrm{~mm})$ for exication and displayed in a peak/area versus area dot plot, with both axis and linear. After discrimination of doublets, fluorescence data were displayed in a 1.024-channel histogram by the use of a linear 4-decade scale. The portion of apoptotic cells was determined by ModFit LT Software (Verity Software House, Topsham, ME, USA).

\section{Acknowledgements}

The authors thank Li-Chuan Huang for technical assistance, Jingjing Tang for assistance with the FACS ${ }^{\circledR}$ analysis, and Barbara Droker for editorial assistance. This work was supported by the National Institutes of Health grants HL18645 (R Ross, EW Raines, AW Clowes) and HL30946 (AW Clowes, RD Kenagy), the Canadian Institutes of Health Research grant MOP 37938 (A Karsan), and the Interdisziplinäres Zentrum für Klinische Forschung (IZKF-11), Münster (B Levkau).

\section{References}

1. Gao W, Bentley RC, Madden JF and Clavien PA (1998) Apoptosis of sinusoidal endothelial cells is a critical mechanism of preservation injury in rat liver transplantation. Hepatology 27: 1652-1660

2. Albon J, Tullo AB, Aktar S and Boulton ME (2000) Apoptosis in the endothelium of human corneas for transplantation. Invest. Ophthalmol. Vis. Sci. 41:2887-2893

3. Benjamin LE, Golijanin D, Itin A, Pode D and Keshet E (1999) Selective ablation of immature blood vessels in established human tumors follows vascular endothelial growth factor withdrawal. J. Clin. Invest. 103: 159-165

4. Meeson AP, Argilla M, Ko K, Witte L and Lang RA (1999) VEGF deprivationinduced apoptosis is a component of programmed capillary regression. Development 126: 1407-1415

5. Levkau B, Herren B, Koyama H, Ross R and Raines EW (1998a) Caspasemediated cleavage of focal adhesion kinase pp125FAK and disassembly of focal adhesions in human endothelial cell apoptosis. J. Exp. Med. 187: 579-586

6. Herren B, Levkau B, Raines EW and Ross R(1998)Cleavage of beta-catenin and plakoglobin and shedding of VE-cadherin during endothelial apoptosis: evidence for a role for caspases and metalloproteinases. Mol. Biol. Cell. 9: $1589-1601$ 
7. Levkau B, Koyama H, Raines EW, Clurman BE, Herren B, Orth K, Roberts JMand Ross R (1998b) Cleavage of p21Cip1/Waf1 and p27Kip1 mediates apoptosis in endothelial cells through activation of Cdk2: role of a caspase cascade. Mol Cell. 1: $553-563$

8. Werb Z(1997) ECM and cell surface proteolysis: regulating cellular ecology. Cell 91: $439-442$

9. Meredith Jr JE, Fazeli B and Schwartz MA (1993) The extracellular matrix as a cell survival factor. Mol. Biol. Cell 4: 953-961

10. Frisch SM and Francis H (1994) Disruption of epithelial cell-matrix interactions induces apoptosis. J. Cell. Biol. 124: 619-626

11. Re F, Zanetti A, Sironi M, Polentarutti N, Lanfrancone L, Dejana E and Colotta F (1994) Inhibition of anchorage-dependent cell spreading triggers apoptosis in cultured human endothelial cells. J. Cell. Biol. 127: 537-546

12. Boudreau N, Sympson CJ, Werb Z and Bissell MJ (1995) Suppression of ICE and apoptosis in mammary epithelial cells by extracellularmatrix. Science 267:891-893

13. Wang N, Butler JP and Ingber DE (1993) Mechanotransduction across the cell surface and through the cytoskeleton [see comments]. Science 260: 1124-1127

14. Clark EA and Brugge JS (1995) Integrins and signal transduction pathways: the road taken. Science 268: $233-239$

15. Schwartz MA, Schaller MD and Ginsberg MH (1995) Integrins: emerging paradigms of signal transduction. Annu. Rev. Cell. Dev. Biol. 11: 549-599

16. Craig SW and Johnson RP (1996) Assembly of focal adhesions: progress, paradigms, and portents. Curr. Opin. Cell. Biol. 8: 74-85

17. Basbaum CB and Werb Z (1996) Focalized proteolysis: spatial and temporal regulation of extracellular matrix degradation at the cell surface. Curr. Opin. Cell. Biol. 8: $731-738$

18. Sympson CJ, TalhoukRS, Alexander CM, Chin JR, Clift SM, Bissell MJ and Werb Z (1994) Targeted expression of stromelysin-1 in mammary gland provides evidence for a role of proteinases in branching morphogenesis and the requirement for an intact basement membrane for tissue-specific gene expression [published erratum appears in J Cell Biol 1996 Feb;132(4):following 752]. J. Cell. Biol. 125: 681-693

19. Karsan A, Yee E, Poirier GG, Zhou P, Craig R and Harlan JM (1997) Fibroblast growth factor-2 inhibits endothelial cell apoptosis by Bcl-2- dependent and independent mechanisms. Am. J. Pathol. 151: 1775-1784

20. O'Mullane MJ and Baker MS (1999) Elevated plasminogen receptor expression occurs as a degradative phase event in cellular apoptosis. Immunol. Cell Biol. 77: $249-255$

21. Sato H, Takino T, Okada Y, CaoJ, Shinagawa A, Yamamoto Eand Seiki M(1994) A matrix metalloproteinase expressed on the surface of invasive tumour cells [see comments]. Nature 370:61-65

22. Hernandez-Barrantes S, Toth M, Bernardo MM, Yurkova M, Gervasi DC, Raz Y, Sang QA and Fridman R (2000) Binding of active (57 kDa) membrane type 1matrix metalloproteinase (MT1-MMP) to tissue inhibitor of metalloproteinase (TIMP)-2 regulates MT1-MMP processing and pro-MMP-2 activation. J. Biol. Chem. 275: $12080-12089$

23. Will H, Atkinson SJ, Butler GS, Smith B and Murphy G (1996) The soluble catalytic domain of membrane type 1 matrix metalloproteinase cleaves the propeptide of progelatinase $A$ and initiates autoproteolytic activation. Regulation by TIMP-2 and TIMP-3. J. Biol. Chem. 271: 17119-17123

24. Baramova EN, Bajou K, Remacle A, L'Hoir C, Krell HW, Weidle UH, Noel A and Foidart JM (1997) Involvement of PA/plasmin system in the processing of pro-MMP9 and in the second step of pro-MMP-2 activation. FEBS Lett. 405: 157-162

25. Brooks PC, Stromblad S, Sanders LC, von Schalscha TL, Aimes RT, StetlerStevenson WG, Quigley JP and Cheresh DA (1996) Localization of matrix metalloproteinase MMP-2 to the surface of invasive cells by interaction with integrin alpha v beta 3. Cell 85: 683-693

26. Partridge CA, Phillips PG, Niedbala MJ and Jeffrey JJ (1997) Localization and activation of type IV collagenase/gelatinase at endothelial focal contacts. Am. J. Physiol. 272: L813-L822

27. Kovach NL, Carlos TM, YeeE and HarlanJM(1992)A monoclonal antibody to beta 1 integrin (CD29) stimulates VLA- dependent adherence of leukocytes to human umbilical vein endothelial cells and matrix components. J. Cell. Biol. 116: 499-509

28. Takada Y and Puzon W (1993) Identification of a regulatory region of integrin beta 1 subunit using activating and inhibiting antibodies. J. Biol. Chem. 268: 17597 17601

29. Bergmann U, Tuuttila A, Stetler-Stevenson WG and Tryggvason K (1995) Autolytic activation of recombinant human 72 kilodalton type IV collagenase. Biochemistry 34: $2819-2825$
30. KheradmandF, WernerE, TrembleP, Symons MandWerbZ(1998) Role of Rac1 and oxygen radicals in collagenase-1 expression induced by cell shape change. Science 280: 898-902

31. Aggeler J, Frisch SM and Werb Z (1984) Changes in cell shape correlate with collagenase gene expression in rabbit synovial fibroblasts. J. Cell. Biol. 98: $1662-1671$

32. Unemori EN and Werb Z (1986) Reorganization of polymerized actin: a possible trigger for induction of procollagenase in fibroblasts cultured in and on collagen gels. J. Cell. Biol. 103: 1021 - 1031

33. Tomasek JJ, Halliday NL, Updike DL, Ahern-Moore JS, Vu TK, Liu RW and Howard EW (1997) Gelatinase A activation is regulated by the organization of the polymerized actin cytoskeleton. J. Biol. Chem. 272: 7482-7487

34. Yan L, Moses MA, Huang Sand IngberDE (2000) Adhesion-dependent control of matrix metalloproteinase-2 activation in human capillary endothelial cells. J. Cell. Sci. 113: 3979-3987

35. Deryugina El, Ratnikov B, Monosov E, Postnova TI, DiScipio R, Smith JW and Strongin AY (2001) MT1-MMP initiates activation of pro-MMP-2 and integrin alphavbeta3 promotes maturation of MMP-2 in breast carcinoma cells. Exp. Cell. Res. 263: 209-223

36. Coleman ML, Sahai EA, Yeo M, Bosch M, Dewar A and Olson MF (2001) Membrane blebbing during apoptosis results from caspase-mediated activation of ROCK I. Nat. Cell. Biol. 3: 339-345

37. Sebbagh M, Renvoize C, Hamelin J, Riche N, Bertoglio J and Breard J (2001) Caspase-3-mediated cleavage of ROCK I induces MLC phosphorylation and apoptotic membrane blebbing. Nat. Cell. Biol. 3: 346-352

38. Chen CS, Mrksich M, Huang S, Whitesides GM and Ingber DE (1997) Geometric control of cell life and death. Science 276: 1425-1428

39. Ruegg C, Yilmaz A, Bieler G, Bamat J, Chaubert P and Lejeune FJ (1998) Evidence for the involvement of endothelial cell integrin alphaVbeta3 in the disruption of the tumor vasculature induced by TNF and IFN-gamma [see comments]. Nat. Med. 4: 408-414

40. Harrington EO, Smeglin A, Newton J, Ballard G and Rounds S (2001) Protein tyrosine phosphatase-dependent proteolysis of focal adhesion complexes in endothelial cell apoptosis. Am. J. Physiol. Lung. Cell. Mol. Physiol. 280: L342 L353

41. StupackDG, PuenteXS, Boutsaboualoy S, Storgard CM and ChereshDA(2001) Apoptosis of adherent cells by recruitment of caspase-8 to unligated integrins. J Cell. Biol. 155: $459-470$

42. Cheresh DA and Stupack DG (2002) Integrin-mediated death: An explanation of the integrin-knockout phenotype? Nat. Med. 8: 193-194

43. Black RA, Rauch CT, Kozlosky CJ, Peschon JJ, Slack JL, Wolfson MF, Castner BJ, Stocking KL, Reddy P, Srinivasan S, Nelson N, Boiani N, Schooley KA, Gerhart M, Davis R, Fitzner JN, Johnson RS, Paxton RJ, March CJ and Cerretti DP (1997) A metalloproteinase disintegrin that releases tumour-necrosis factoralpha from cells. Nature 385: $729-733$

44. Kwaan HC, Wang J, Svoboda K and Declerck PJ (2000) Plasminogen activator inhibitor 1 may promote tumour growth through inhibition of apoptosis. Br. J. Cancer 82: 1702-1708

45. Kamphaus GD, Colorado PC, Panka DJ, Hopfer H, Ramchandran R, Torre A, Maeshima Y, Mier JW, Sukhatme VP and Kalluri R (2000) Canstatin, a novel matrix-derived inhibitor of angiogenesis and tumor growth. J. Biol. Chem. 275: $1209-1215$

46. Maeshima $\mathrm{Y}$, Yerramalla UL, Dhanabal M, Holthaus KA, Barbashov S, Kharbanda S, Reimer C, Manfredi M, Dickerson WM and Kalluri R (2001) Extracellular matrix-derived peptide binds to alpha(v)beta(3) integrin and inhibits angiogenesis. J. Biol. Chem. 276: 31959-31968

47. Buckley CD, Pilling D, Henriquez NV, Parsonage G, Threlfall K, Scheel-Toellner D, Simmons DL, Akbar AN, Lord JM and Salmon M (1999) RGD peptides induce apoptosis by direct caspase-3 activation [see comments]. Nature 397:534-539

48. Gospodarowicz D, Cheng J and Lirette M (1983) Bovine brain and pituitary fibroblast growth factors: comparison of their abilities to support the proliferation of human and bovine vascular endothelial cells. J. Cell. Biol. 97: 1677-1685

49. Clowes AW, Clowes MM, Au YP, Reidy MA and Belin D (1990) Smooth muscle cells express urokinase during mitogenesis and tissue- type plasminogen activator during migration in injured rat carotid artery. Circ. Res. 67: 61-67

50. Kenagy RD, Nikkari ST, Welgus HG and Clowes AW (1994) Heparin inhibits the induction of three matrix metalloproteinases (stromelysin, 92-kD gelatinase, and collagenase) in primate arterial smooth muscle cells. J. Clin. Invest. 93: 19871993 